\title{
Energy recovery from domestic radiators using a compact composite metal Foam/PCM latent heat storage
}

\author{
Pouyan Talebizadeh Sardari ${ }^{\mathrm{a}, *}$, Rohollah Babaei-Mahani ${ }^{\mathrm{b}}$, Donald Giddings ${ }^{\mathrm{a}}$, Sirous Yasseri $^{\mathrm{c}}$, \\ Mohammad Moghimi Ardekani ${ }^{\mathrm{d}}$, Hamid Bahai ${ }^{\mathrm{c}}$ \\ a Faculty of Engineering, University of Nottingham, University Park, Nottingham, NG7 2RD, United Kingdom \\ b Director, Belmore Energy Ltd., London, United Kingdom \\ ${ }^{\mathrm{c}}$ Department of Mechanical and Aerospace Engineering, Brunel University London, Howell Building, Brunel University, Uxbridge, UB8 3PH, United Kingdom \\ d Department of Design and Engineering, Staffordshire University, Stoke-on-Trent, ST4 2DE, United Kingdom
}

\section{A R T I C L E I N F O}

\section{Article history:}

Received 27 June 2019

Received in revised form 17 January 2020

Accepted 9 Febraury 2020

Available online $\mathrm{xxx}$

Handling editor: Kathleen Aviso

\section{Keywords}

Latent heat storage

Compact design

Phase change material

Porous medium

Radiator

Charging/discharging

\begin{abstract}
A B S T R A C T
With the increasing demand for energy consumption in domestic buildings and consequent $\mathrm{CO}_{2}$ emission, there is a need to provide proper products to reduce energy loss. Domestic radiators for space heating can be improved by using a Compact Latent Heat Storage (CLHS) unit mounted on the wall side surface in order to offer energy saving and peak-shaving. The unit offers the potential to save otherwise wasted energy from the back surface of the radiator to the walls in the charging mode of the energy storage system. When the heating system is turned off, the CLHS unit discharges the stored heat towards the room to provide a uniform temperature on the surface of the radiator. An aluminium foam embedded inside the bulk Phase Change Material (PCM) can modify the heat storage/retrieval rate. A PCM is selected depending on the radiator's surface temperature, which is almost equal to the hot water temperature delivered to the radiator. Different metal foam porosities are examined and compared with the PCM-only alternative (i.e. without metal foam enhancement). The results show the porous-PCM CLHS alternative provides an almost constant temperature during the discharging process equal to $54{ }^{\circ} \mathrm{C}$. However, for the PCM-only alternative, the temperature of the surface reduces continuously. Using the porous medium results in a shorter melting time, about $95 \%$ of what is needed for the PCM-only alternative. Increasing the metal foam porosity results in shorter charging/discharging time; however, since the surface temperature of the porous-PCM unit is almost constant for different metal foam porosities, a system with higher porosity (97\%) is desirable.
\end{abstract}

(C) 2020

\begin{tabular}{|ll|}
\hline Nomenclature \\
$A_{m}$ & Mushy zone \\
$C$ & Inertial coefficient \\
$C_{p}$ & PCM Specific heat $(\mathrm{J} / \mathrm{kgK})$ \\
$e_{e}$ & Total energy at the end of the charging/discharging \\
& process $(\mathrm{J})$ \\
$e_{i}$ & Total energy at the initial of the charging/discharging \\
& process $(\mathrm{J})$ \\
$g$ & Gravity $\left(\mathrm{m} / \mathrm{s}^{2}\right)$ \\
$H$ & Height of the unit (m) \\
$k_{p c m}$ & Fluid Thermal conductivity $(\mathrm{PCM})(\mathrm{W} / \mathrm{mK})$ \\
$k_{\text {porous }}$ & Porous medium Thermal conductivity $(\mathrm{W} / \mathrm{mK})$ \\
$K$ & Permeability (m $\left.{ }^{2}\right)$ \\
$L$ & Fusion Latent heat of PCM $(\mathrm{J} / \mathrm{kg})$
\end{tabular}

\footnotetext{
* Corresponding author.

E-mail address: pouyan.talebizadehsardari@nottingham.ac.uk (P.T. Sardari)
}

\begin{tabular}{|ll|}
\hline$m$ & PCM mass (kg) \\
$P$ & Pressure (Pa) \\
$P r$ & Prandtl number \\
$Q$ & Capacity of heat storage/retrieval $(\mathrm{J})$ \\
$R a$ & Rate of heat storage/retrieval $(\mathrm{W})$ \\
$t_{m}$ & Rayleigh number \\
$T$ & Charging/Discharging time (s) \\
$T_{e}$ & Temperature (K) \\
& Temperature at the end of the charging/discharging \\
$T_{i}$ & process(K) \\
$T_{r e f}$ & Initial temperature (K) \\
$\vec{V}$ & Reference temperature (K) \\
$\mathrm{Greek}$ symbols & \\
$\beta$ & Thermal expansion coefficient $(1 / \mathrm{K})$ \\
$\varepsilon$ & Porosity \\
$\lambda$ & Liquid fraction \\
$\mu$ & Dynamic viscosity $(\mathrm{kg} / \mathrm{ms})$ \\
$\rho$ & PCM Density $\left(\mathrm{kg} / \mathrm{m}^{3}\right)$ \\
\hline
\end{tabular}




\section{$\Delta H \quad$ Latent heat $(\mathrm{J} / \mathrm{kg})$}

$\Delta P \quad$ Pressure drop $(\mathrm{Pa})$

\section{Introduction}

New technologies recovering heat from domestic space and water heating could make a significant impact on energy consumptiosn and $\mathrm{CO}_{2}$ reduction while improving the quality of life ( $\mathrm{Yu}$ et al., 2019). Among all energy consumed by end-users, domestic space heating accounts for $45-47 \%$ and water heating accounts for another $40 \%$ (Marique et al., 2014). In the UK, in 2015, buildings were responsible for $29 \%$ of the total final energy consumption according to the department for Business, Energy and Industrial Strategy which increased by $3.1 \%$ in 2016 (BIES, July 2017). In 2016, the residential sector was accounted for $18 \%$ of all $\mathrm{CO}_{2}$ emissions which is $4.5 \%$ higher than that in 2015 (BEIS, March 2017). Any attempt to reduce the consumption, without impact in the quality of life, or even curb it will be beneficial to the nation and also the environment (Irshad et al., 2019). Recovering and storing heat can contribute substantially toward this goal (Yong et al., 2016).

Among different energy storage technologies, Thermal Energy Storage (TES) provides an effective peak-shaving technology used in thermal energy demand, efficient use of energy, recovery from low-grade heat waste, as well as uniformity of the distributed energy and backup energy systems (Kabeel, A. E. et al., 2019a,b; Shaibani et al., 2019). In Europe, around 1.4 million GWh/year and 400 million tons of $\mathrm{CO}_{2}$ emissions are estimated to be saved by TES (Sarbu and Sebarchievici, 2016). Considering different TES types, Latent heat storage (LHS) systems have great potential to provide a cost-effective solution for this problem by introducing Phase change materials (PCMs) to store and release thermal energy. PCMs are also capable to compete with other sensible heat storage materials such as $\mathrm{MgO}$ in terms of cost per $\mathrm{kWh}$, and are far more compact and also cheaper than electrochemical thermal storages (Kabeel et al., 2019a,b). They have an energy density typically 5 to 14 times higher than any rival thermal energy storage systems and have the added advantage of having almost constant temperature during the phase change process (Khan et al., 2016). Thus, this is a significant importance to world energy demands, economy, and quality of life.

The main challenges for efficient use of PCM-based technology are the long melting/solidification time as well as inefficient releasing/gaining heat due to low thermal conductivity and low thermal diffusivity within the bulk PCM (Sheikholeslami, 2018a) led to limited use of LHS systems (Pereira da Cunha and Eames, 2016). However, among different enhancement methods for the heat storage/retrieval rate including geometry modification (Dadollahi and Mehrpooya, 2017; El-Said et al., 2018; Shahsavar et al., 2019c), use of fins (El-Said and Abou Al-Sood, 2019; El-Said and Alsood, 2018; Shahsavar et al., 2019b), use of nanoparticles (Sheikholeslami, 2018b), use of encapsulation (Jamekhorshid et al., 2014) and use of porous structures (Zhao, 2012), employing high conductivity metal foam provides a promising technology to solve this problem.

In the composite porous/PCM combination, the thermal energy is transferred by conduction through the porous foam rather than PCM which increases the rate of thermal diffusion (Shahsavar et al., 2019a). It was shown that the effect of conduction heat transfer by the porous foam is to significantly modify the charging/discharging process (Zhang et al., 2017). Py et al. (2001) presented that the effective thermal conductivity of a paraffin-based heat storage system with graphite foam increases to the range from 4 to $70 \mathrm{~W} / \mathrm{mK}$ instead of almost $0.2 \mathrm{~W} / \mathrm{mK}$ for paraffin. Mesalhy et al. (2005) recommended a PCM storage unit with high porosity and high thermal conductivity of the foam due to the reduction of the convection effect due to the use of the porous medium. Liu et al. (2013) studied numerically the melting process of a composite metal foam/PCM shell and tube energy storage system. They showed the low effect of pore size on the melting process and the negligible effect of natural convection because of high flow resistance in the porous medium (Mohammed et al., 2019). Mahdi et al. (2018) studied a double tube LHS system using multiple-segment metal foam with various porosities. They presented that the use of different foam porosities in different segments enhances the rate of heat storage and recovery compared with the single porosity case. Shahsavar et al. (2019a) employed the geometry modification simultaneous with the porous medium to enhance the heat transfer rate in a cylindrical LHS unit showing more than $90 \%$ reduction in melting/solidification time. Sheikholeslami and Mahian (2019) studied the effect of magnetic field on the solidification process of a nano-PCM embedded in a porous annulus. They showed that the addition of nanoparticles reduce the solidification time by $14 \%$ while applying the magnetic field enhances the solidification process by $23.5 \%$. Li et al. (2020) investigated on the simultaneous effects of nanoparticles and porous medium addition showing the negligible effect of nanoparticles in the presence of metal foams.

There are a few studies reported on the application of latent heat storage heat exchangers (LHSHE) for room heating and ventilation in the literature (Campos-Celador et al., 2014). Wang et al. (2006) performed an experimental study on a type of high-temperature LHS air heater in a room with the aim of providing electricity for peak hours from off-peak hours. They used electrical elements to charge the PCM with high latent heat and high melting point. The results show that by charging the system for $8 \mathrm{~h}$, the system can provide suitable thermal energy for room heating in the remaining $16 \mathrm{~h}$. Dechesne et al. (2014) studied a PCM air heat exchanger in a ventilation system. In their study, the thermal energy gained from the Photovoltaic modules is stored during the day and released to the room during the night. For the cooling purpose, coolness is stored during the night and released to the room during the day. They developed a semi-empirical equation for the outlet temperature of the air. The system can provide more than $50 \mathrm{~W}$ of cooling and heating powered by the PCM heat exchanger over $5 \mathrm{~h}$. Osterman et al. (2015) prepared a PCM storage unit suitable for both cooling and heating purposes. During summer, the system stores cold from the outdoor air at night to reduce the required cooling load during the daytime. During winter, the system stores heat from the air heated by solar collectors. They showed, $142 \mathrm{kWh}$ energy consumption of an office can be saved annually. Wang et al. (2015) studied a PCM to air energy exchanger with a zigzag plate geometry using different unequal mass PCMs with various melting points. They validated their model with the experimental data using $\mathrm{NaCl}-\mathrm{MgCl}_{2}$ salt. They showed the advantage of using a combination of PCMs instead of PCM-only. They showed that there is a time period within which the outlet temperature is almost equal to the initial temperature depending on the melting points of the employed PCM. Sardari et al. (2020) studied the application of combined metal foam and PCM for domestic space heating by introducing a novel energy storage heater. They proved the capability of composite metal foam-PCM on providing uniform output temperature from a domestic dwelling heater. They used RT82 with the melting point of $82{ }^{\circ} \mathrm{C}$ for the PCM suitable for space heating. In another study (Sardari et al., 2019a), they examined different aspect ratios of the heat exchanger to provide a uniform output temperature during 16-h discharge.

The aim of this paper is to employ composite metal foam-PCM in a compact latent heat storage (CLHS) unit adapted for commercially available radiators. The unit gains thermal energy from the radiator which can be used during the peak-load hours for domestic space heating. For this purpose, the system is designed to be fitted in the space at the back of the radiator to absorb and release thermal energy from and to the radiator, respectively. Aluminium foam is employed to in- 
crease the rate of heat transfer inside the PCM to provide an acceptable rate of charging and discharging. The objective of this study is to find out if the system can provide a uniform temperature on the radiator's surface during the discharging process. Furthermore, the system is analysed in the charging process to determine the charging time and find out if the system can be thermally charged from the radiator in a suitable time. The idea of the proposed CLHS unit is introduced for the first time in this paper which presents a compact unit added to the existing heating systems inside buildings which can contribute significantly to energy-saving and peak shaving opportunities in buildings with the consequent reduction of associated energy production emissions.

\section{System description}

The objective is to develop a compact composite storage unit that can be added to the back-side of current radiators. The unit's dimensions were obtained based on the size of a commercially available radiator and the possible space at the back of the radiator. The unit is a rectangular thin enclosure, which is thin enough to be placed at the back of a radiator to store the excess thermal energy, and then release it during peak hours in order to turn off the boiler and save energy aiming to maintain a constant temperature on the radiator surface. The schematic of the entire system is displayed in Fig. 1. It is worth mentioning that for the fabrication of the composite metal foam-PCM unit, in a vacuumed environment, the PCM is melted and penetrated inside the pores of the foam and then solidified to make the composite block. A detailed description of the method was presented in the literature (Shang et al., 2018; Xiao et al., 2013)

The dimensions of the CLHS unit are $100 \mathrm{~cm} \times 50 \mathrm{~cm} \times 2 \mathrm{~cm}$. The unit includes an Aluminium foam with the pore density of 30 PPI using RT54HC as the PCM. The porous-PCM alternative with different porosities is compared with the PCM-only alternative. Note that all the surfaces of the LHS, except the front wall, are considered as adiabatic. Constant temperature and convection heat transfer are considered as the front wall boundary conditions in the charging and discharging mechanisms, respectively. The detailed description of the boundary conditions is presented in Section 4. In addition to the novel proposed application, this study assesses the effect of utilization of a porous medium in a low thickness heat storage system. Note that in the case of porous-PCM, the height of the unit is increased based on the volume of the foam in order to have similar PCM masses in different cases equal to the PCM-only alternative to have a meaningful comparison.

RT54HC has a suitable melting point for domestic usage, especially for the radiator system. The temperatures of radiators are generally in the range of $50-70{ }^{\circ} \mathrm{C}$ which is assumed to be $60{ }^{\circ} \mathrm{C}$ in this study. RT54HC is also suitable for domestic application considering a high latent heat of fusion which allows the system to store more thermal energy per unit mass. The properties of RT54HC are presented in Table 1.

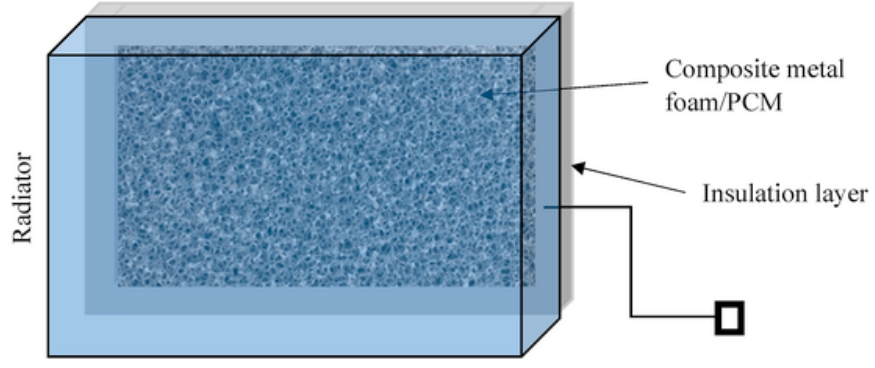

Fig. 1. The schematic of the CLHS unit at the back-side of the radiator
Table 1

Physical properties of RT54HC (Rubitherm GmbH)

\begin{tabular}{ll}
\hline Property & RT 54HC \\
\hline Solidus/Liquidus temperature & $53 / 54\left({ }^{\circ} \mathrm{C}\right)$ \\
Latent heat of fusion & $200(\mathrm{~kJ} / \mathrm{kg})$ \\
Specific heat & $2.0(\mathrm{~kJ} / \mathrm{kg} \cdot \mathrm{K})$ \\
Solid/Liquid Density & $850 / 800\left(\mathrm{~kg} / \mathrm{m}^{3}\right)$ \\
Thermal conductivity & $0.2(\mathrm{~W} / \mathrm{m} . \mathrm{K})$ \\
Viscosity & $0.00365(\mathrm{~Pa} . \mathrm{s})$ \\
Thermal expansion coefficient & $0.000308(1 / \mathrm{K})$ \\
\hline
\end{tabular}

\section{Mathematical description}

For the PCM-only system, in the PCM solid state, thermal energy is transferred by conduction and then, after generating the liquid phase, transferred by both conduction and natural convection. In the porous-PCM alternative, heat transfer is enlarged by the metal foam inside the PCM rather than low conductivity PCM and the effect of natural convection is negligible (Py et al., 2001). The detailed mathematical modelling and the governing assumptions can be found in (Sardari et al., 2019c). A thermal equilibrium model is used to model the porous structure inside the PCM with the aid of an enthalpy-porosity method for the phase change effect. In the thermal equilibrium model, an equal temperature is considered for both the PCM and porous structure. A brief description of the governing equations, considering incompressible Newtonian fluid for the PCM in laminar flow regime, is discussed as follows (Sardari et al., 2019c):

$$
\begin{aligned}
& \frac{\partial \rho}{\partial t}+\nabla \cdot \rho \vec{V}=0 \\
& \rho \frac{\partial \vec{V}}{\partial t}+\rho(\vec{V} \cdot \nabla) \vec{V}=-\nabla P+\mu\left(\nabla^{2} \vec{V}\right) \\
& -\rho_{\text {ref }} \beta \varepsilon\left(T-T_{\text {ref }}\right) \vec{g}-\vec{S}-\vec{F} \\
& \frac{\partial \varepsilon \rho C_{p} T}{\partial t}+\nabla\left(\rho C_{p} \vec{V} T\right)=\nabla\left(k_{e} \nabla T\right)-S_{L}
\end{aligned}
$$

where $k_{e}$ is defined as the volume average between the thermal conductivities of the porous medium and PCM as (Liu et al., 2013):

$k_{e}=(1-\varepsilon) k_{\text {porous }}+\varepsilon k_{P C M}$

In the momentum equation, the Boussinesq approximation is employed to consider the effect of natural convection (Sardari et al., $2019 b$ ). Note that the PCM volume expansion is neglected. The source term $(\vec{S})$ is given as (Mahdi and Nsofor, 2017):

$\vec{S}=A_{m} \frac{(1-\lambda)^{2}}{\lambda^{3}+0.001} \vec{V}$

where $A_{m}$ is $10^{5}$ (Assis et al., 2007; Ye et al., 2011). The porous medium is assumed to be open-cell, homogeneous and isotropic. For the PCM-only, the porosity is considered one in the governing equations. Additionally, $\lambda$ is defined as (Sardari et al., 2019b):

$$
\begin{aligned}
& \lambda=\frac{\Delta H}{L} \\
& =\left\{\begin{array}{lrr}
0 & \text { if } T<T_{\text {Solidus }} \\
1 & \text { if } T>T_{\text {Liquidus }} \\
\frac{T-T_{\text {Solidus }}}{T_{\text {Liquidus }}-T_{\text {Solidus }}} & \text { if } \quad T_{\text {Solidus }}<T<T_{\text {Liquidus }}
\end{array}\right\}
\end{aligned}
$$

where $\Delta H$ is the latent heat vary between zero for the solid state and $L$ for the liquid state. 
The body force $(\vec{F})$ is defined as (Sardari et al., 2019c):

$\vec{F}=\left(\frac{\mu}{K}+\frac{\rho C|\vec{V}|}{\sqrt{K}}\right) \vec{V}$

The formulation related to the calculation of $K$ and $C$ can be found in Ref. (Shahsavar et al., 2019a). $S_{L}$ in the energy equation is defined as (Wang et al., 2015):

$S_{L}=\frac{\partial \varepsilon \rho \lambda L}{\partial t}+\nabla(\rho \vec{V} \lambda L)$

The rate of heat storage and retrieval can be calculated as the ratio of the storage/retrieval capacity to the melting/solidification time given as (Xu et al., 2017):

$\dot{Q}=\frac{Q}{t_{m}}=\frac{m\left(\int_{\text {solid }} C_{p} d T+L_{f}+\int_{\text {liquid }} C_{p} d T\right)}{t_{m}}=\frac{m\left(e_{e}-e_{i}\right)}{t_{m}} \approx \frac{m\left(C_{p}\left(T_{m}-\right.\right.}{}$

It should be noted that in the thermal equilibrium model, the temperatures of the PCM and porous medium are assumed to be similar. This assumption is justified for phase change since most of the phase change process happens when the temperature is almost constant (Mahdi et al., 2020).

\section{Charging/discharging mechanism}

In the charging process, the LHS unit is fixed at the back surface of the radiator to gain heat from the radiator's surface with a constant wall temperature. The constant temperature of $60{ }^{\circ} \mathrm{C}$ is used for the radiator's wall and all the other walls are assumed to be insulated.

For the discharging process, the convection boundary condition is imposed for the front wall of the unit with an ambient temperature equals to $21{ }^{\circ} \mathrm{C}$. It is also assumed that no water exists in the radiator's surface and the heat is transferred from the composite PCM to the ambient by radiator's wall made from aluminium. The convection coefficient between the front wall and ambient is calculated at the film temperature considering the wall temperature at the PCM melting point $\left(54^{\circ} \mathrm{C}\right)$. In the laminar range, for a vertical wall, the convection coefficient is calculated based on the experimental data given as (Be- jan, 2013):

$\bar{h}=\frac{k \overline{N u}}{H}=\frac{k}{H}\left(0.68+\frac{0.67 R a^{1 / 4}}{\left[1+(0.492 / P r)^{9 / 16}\right]^{4 / 9}}\right.$

It is noteworthy that for thermal comfort purposes, according to ASHRAE standard, the ambient air temperature inside the room should be in the range of $19.5{ }^{\circ} \mathrm{C}$ and $27.8^{\circ} \mathrm{C}$ which is assumed to be $21{ }^{\circ} \mathrm{C}$ in this study (Bejan, 2013). The aim is to maintain the room temperature in the range of thermal comfort temperature without turning on the boiler. Therefore, in the charging process, the aim is to find the time that the CLHS unit is fully charged and the temperature rises to the radiator's surface temperature when the boiler is working. In the discharging mode, the aim is to find if the unit can provide a uniform temperature on the radiator's surface, and then find the time that the unit can provide a constant temperature on the radiator's surface.

\section{Numerical modelling and validation}

ANSYS-FLUENT is utilized to discretise the equations using the SIMPLE algorithm with double-precision accuracy. PRESTO and QUICK schemes are employed for the pressure correction equation as well as momentum and energy equations, respectively, considering $10^{-6}$ for the convergence criteria for all the equations. Fig. 2 displays the entire computational mesh, showing meshes on the front and sides. It includes $100000(100 \times 100 \times 10)$ cells with the dense mesh near the walls especially in the $y$-direction to capture the effect of gravity. Note that due to symmetry condition, only half of the domain is modelled.

Different cell sizes are also studied for the grid independency analysis and the results are is presented in Table 2 for the PCM-only alternative. The results show a negligible difference between the results of 144000 and 100000 elements for the number of cells. Therefore, 100000 elements are selected for the grid size.

Two time-steps of 0.5 and $0.25 \mathrm{~s}$ for the grid size of 100000 cells are studied for the porous-PCM case. No significant variation was seen in the mechanism of charging/discharging. For the PCM-only system, $0.25 \mathrm{~s}$ is selected for the time step size.

For the porous-PCM simulation, the results of Liu et al. (2013) are employed to verify the applied model employing a $95 \%$ porosity copper foam/PCM using RT-58 in a rectangular enclosure. Fig. 3 illustrates the temperature variation at the height of $8 \mathrm{~mm}$ showing an excellent agreement.

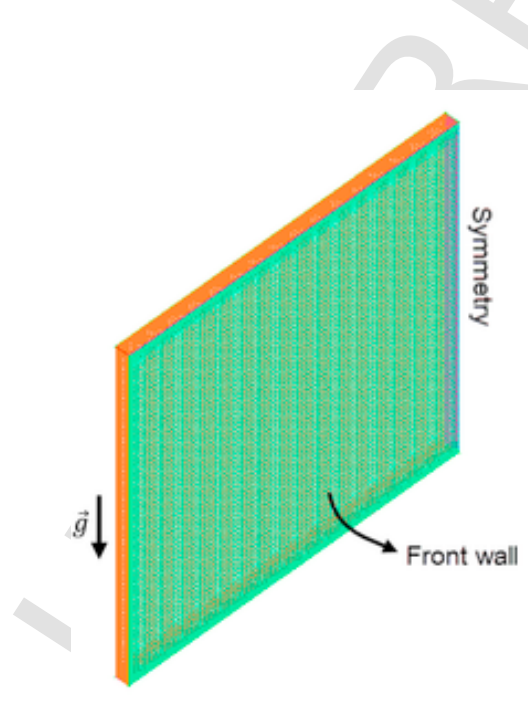

a)

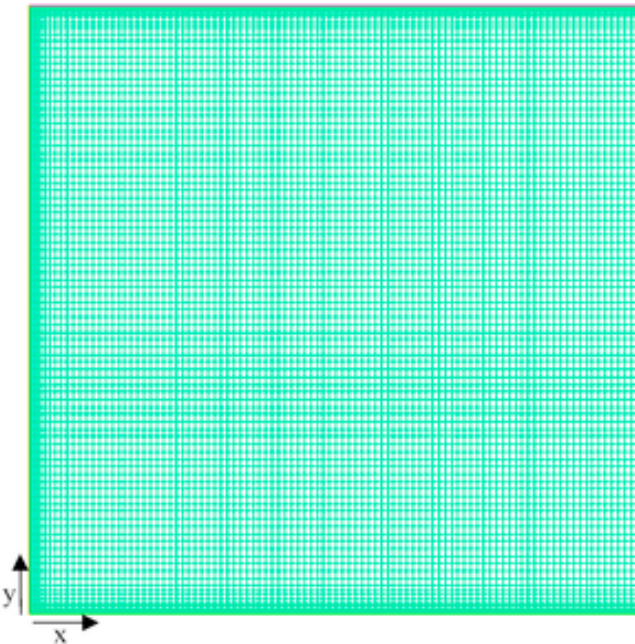

b)

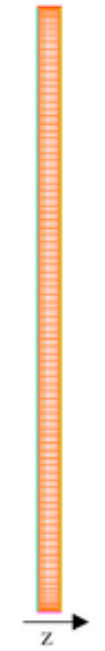

c)

Fig. 2. The schematic of the computation domain with 100000 elements. 
Table 2

Effect of elements number on the melting/solidification time.

\begin{tabular}{lll}
\hline Number of elements & Melting time (h) & Solidification time (h) \\
\hline 64000 & 19283 & 74239 \\
100000 & 20625 & 76010 \\
144000 & 20842 & 76284 \\
\hline
\end{tabular}

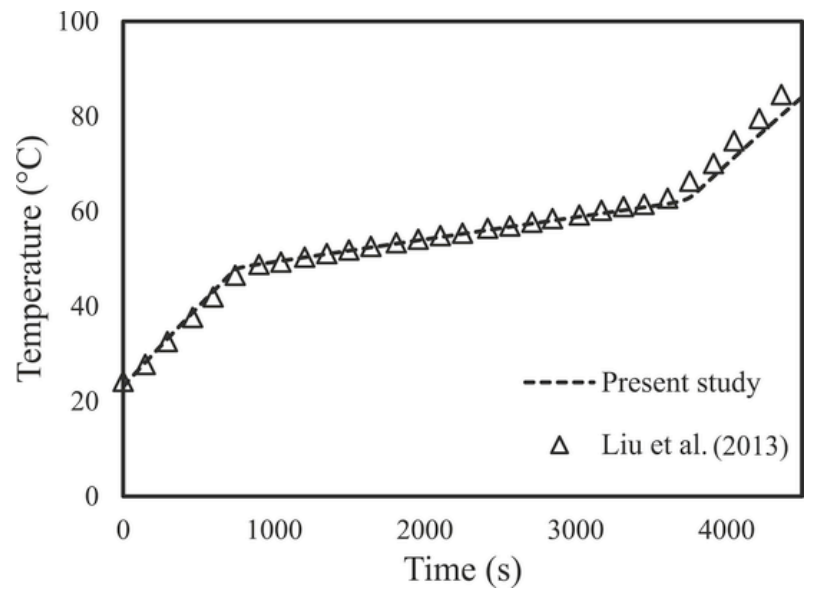

Fig. 3. Code verification compared with the study of Liu et al. (2013).

To study the code verification for the PCM-only alternative, the experimental and numerical results of Mat et al. (Al-Abidi et al., 2013) are employed. Fig. 4 illustrates the average temperature and the liquid fraction in a triple tube fined LHS unit showing an excellent agreement.

\section{Results and discussion}

This section is devoted to discuss the two operating modes of the unit (the charging and discharging modes) which are presented as follows:

\subsection{Charging mode}

In the charging mode, the front wall of the CLHS unit gains heat from the constant wall temperature of the radiator. During the charging mode, the charging time is a key parameter and a shorter charging time is desirable. When the heat storage is completed, the boiler can be turned off and the radiator can retrieve the heat from the unit. In this study, three different porosities (95\%, 97\% and 99\%) are examined for the metal foam and compared with the PCM-only alternative.

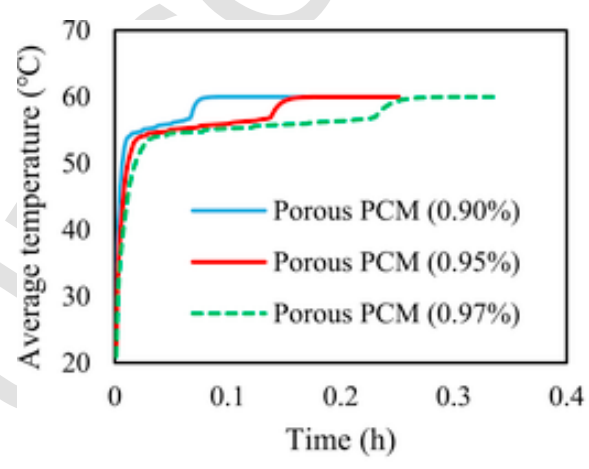

a)

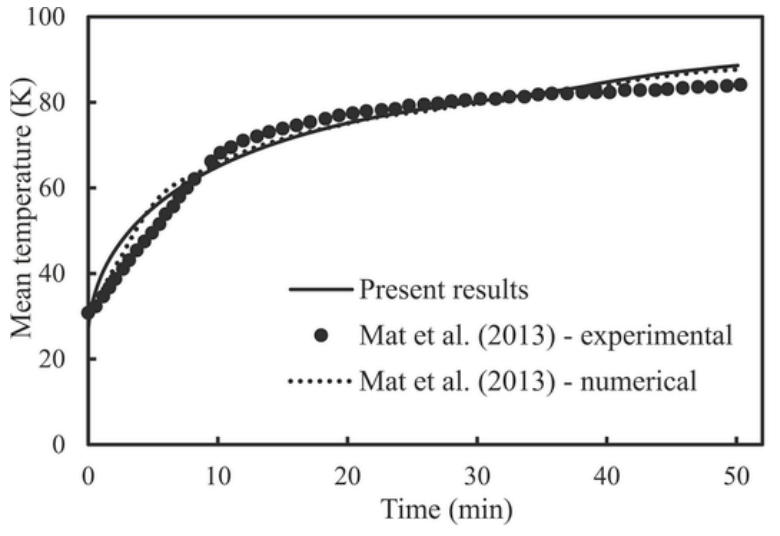

a)

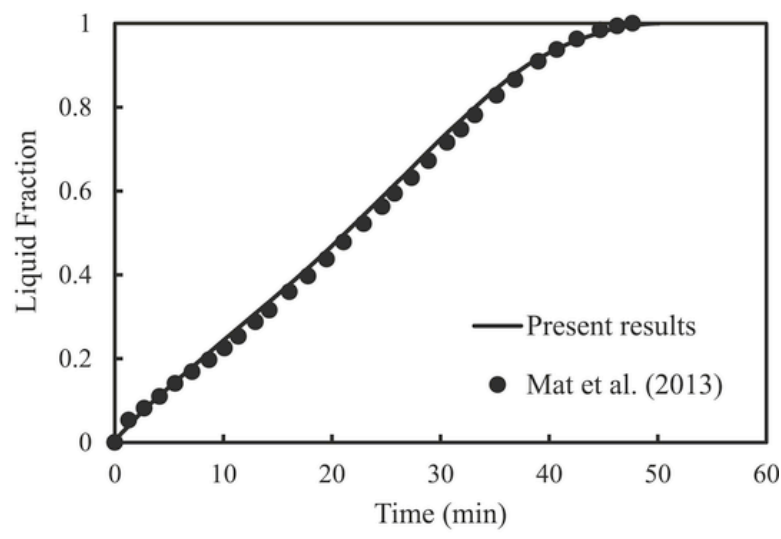

b)

Fig. 4. Code verification for the (a) average temperature and (b) liquid fraction for the PCM-only unit compared with the study of Mat et al. (2013).

Fig. 5 displays the PCM's average temperature in terms of time for the porous-PCM alternatives compared with the PCM-only alternative. The temperature rises rapidly in the porous-PCM alternative due to the high conductivity of the aluminium foam. In the presence of metal foam, the heat is transferred by conduction through the porous foam rather than PCM on its own, which enhances the effective thermal conductivity and the rate of thermal diffusion (Sardari et al., 2019b). In the PCM-only alternative, in the beginning, the heat is transferred by conduction through the low conductivity PCM. Note that the conductivity of Aluminium and PCM are about 200 and $0.2 \mathrm{~W} / \mathrm{m} . \mathrm{K}$ and the volume average conductivity of the porous-PCM is $20.18 \mathrm{~W} / \mathrm{m}$.K. In the PCM-only alternative, after melting a part of the PCM, natural convec-

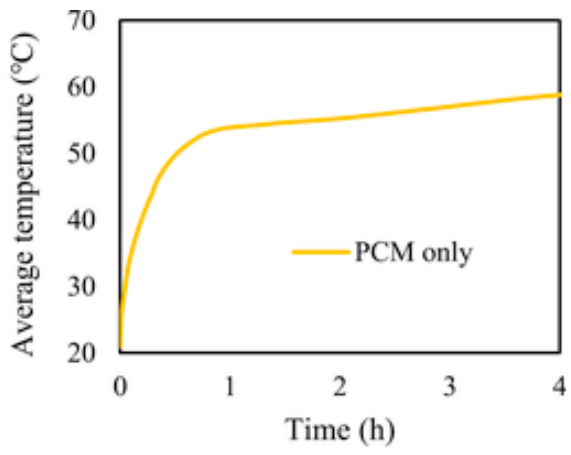

b)

Fig. 5. The variation of PCM average temperature for a) porous-PCM and b) PCM-only alternatives. 
tion is generated in the liquid PCM helping to diffuse heat in the domain (Shahsavar et al., 2020). However, as shown, the effect of natural convection in the PCM-only alternative is negligible compared with the porous-PCM alternative. Note that in the porous-PCM alternative, the effect of natural convection is negligible since the porous structure causes the movement of liquid PCM to slow down and thus suppresses the effect of natural convection (Li et al., 2020). For example, if the porosity is $95 \%$, after almost 600 s, the PCM temperature rises to the temperature of the front wall $\left(60{ }^{\circ} \mathrm{C}\right)$ while the same process takes $4 \mathrm{~h}$ for the PCM-only alternative.

To understand the effect of metal foam, temperatures at different locations in the $\mathrm{x}$-direction (perpendicular to the front wall) is shown in Fig. 6. Note that $\mathrm{x}=0 \mathrm{~cm}$ means the temperature of the front wall, which is constant at $60^{\circ} \mathrm{C}$. In the porous-PCM alternative, due to the presence of the aluminium foam, thermal energy transfers very fast. As shown, after 600 s, all points have the same temperature similar to the front wall. The temperature rises sharply from the initial temperature $\left(21^{\circ} \mathrm{C}\right.$ ) and then remains almost constant during the phase change from the solidus temperature $\left(53{ }^{\circ} \mathrm{C}\right)$ to the liquidus temperature $\left(54{ }^{\circ} \mathrm{C}\right)$, and then again rises sharply. In contrast, in the PCM-only alternative, due to the low thermal conductivity of the PCM and low rate of thermal diffusion, the temperatures of all points reach $60{ }^{\circ} \mathrm{C}$ after almost $3.5 \mathrm{~h}$. Furthermore, after almost $1 \mathrm{~h}$, the temperatures of different points rise to the solidus temperature, results in starting the phase change process.

Fig. 7-a displays the liquid fraction contour plots at the mid-plane section for the porous-PCM alternative with the porosity of $95 \%$ dur-

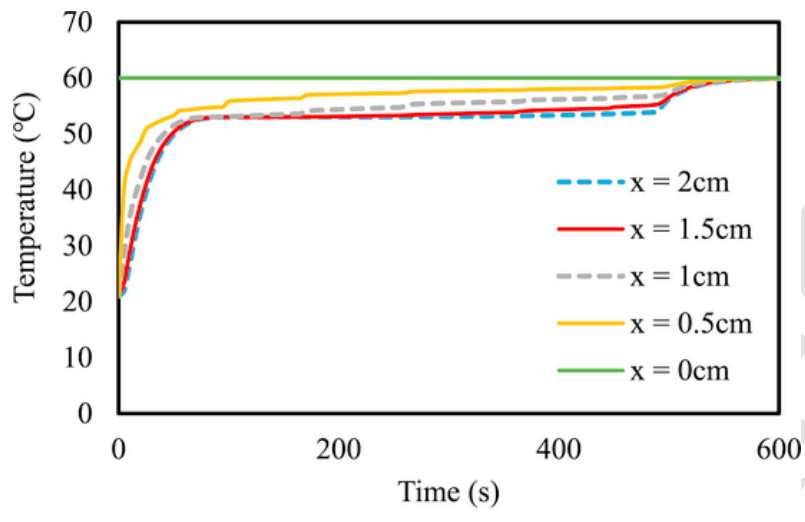

a)

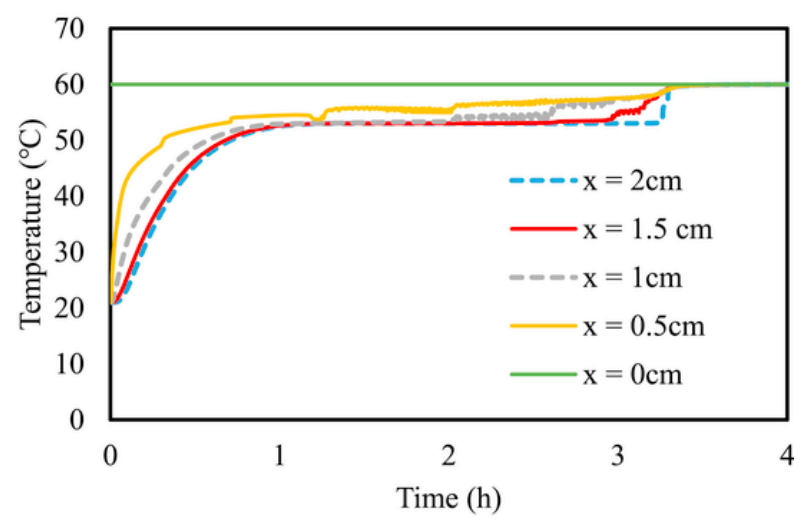

b)

Fig. 6. The variation of PCM temperature at different points in the x-direction for a) porous-PCM $(\varepsilon=95 \%)$ and b) PCM-only alternatives. ing the charging mode at $100 \mathrm{~s}$ time intervals and Fig. 7-b illustrates the same plots for the PCM-only alternative at $1 \mathrm{~h}$ time intervals. Note that for the displayed figures, due to the small thickness of the unit $(2 \mathrm{~cm})$, ratios between the width and height is exaggerated to better show the contours of liquid fraction. The dimensions of the unit, as well as the hot surface, are shown in the first picture of Fig. 7-a.

Due to the presence of metal foam, as displayed in Fig. 7-a, the heat is transferred by conduction throughout the system. The interface line between the solid and liquid phases moves from the hot surface (front wall) to the back of the heat storage unit. Note that the interface line is almost smooth due to conduction heat transfer. However, as shown for the PCM-only alternative (Fig. 7-b), natural convection is taking place in the liquid zone helping to transfer heat better in the domain results in a non-uniform temperature profile. The liquid PCM moves upward near the hot surface and then generates an anticlockwise flow circulation by moving downward near the cold solid region. Furthermore, the PCM melts after almost $6 \mathrm{~h}$ for the PCM-only alternative while after $10 \mathrm{~min}$, the PCM melts entirely for the porous-PCM alternative.

Fig. 8 plots the liquid fraction variation for different porous-PCM alternatives compared with the PCM-only alternative. The porous-PCM alternatives can store heat much faster compared with the PCM-only alternative due to the effects of high conductivity aluminium foam. Furthermore, due to the small thickness of the compact unit and big surface area of the heat source in this application, the heat is transferred rapidly results in short charging time.

Table 3 summarizes the charging time, the total energy storage capacity and the rate of heat storage of the porous-PCM alternatives compared with the PCM-only alternative. The percentage of time-saving compared with the PCM-only unit is also presented. According to the Eq. (9), the storage capacity is $2293.5 \mathrm{~kJ}$ considering the endpoint temperature of $60{ }^{\circ} \mathrm{C}$ equal to the radiator's surface temperature and the initial temperature equals to the comfort temperature of the room. The amounts of heat storage presented in Table 3 for different cases are calculated based on the results of total energy difference in the domain obtained from FLUENT software. The small difference is due to the temperature of the PCM at the end of the simulation, which is slightly different for various cases. Reducing the porosity results in a higher amount of aluminium in the domain which increases the rate of heat transfer and therefore higher heat storage rate is achieved. The rate of heat storage for the porosity of $90 \%$ is more than twice of that for the porosity of $95 \%$.

Based on the results achieved from this section, it can be concluded that with the help of high conductivity porous medium, almost $2266 \mathrm{~kJ}$ thermal energy can be stored in less than 9 min. In other words, the CLHS unit uses the thermal energy of the radiator for just $9 \mathrm{~min}$ from the back surface of the radiator which is then used during the discharging process.

\subsection{Discharging mode}

During the discharging mode, the heat is released from the unit to the environment through the front wall. Instead of the constant temperature condition for the front wall during the charging mode, the convection boundary condition is imposed on the front wall in the discharging mode when the room temperature is $21{ }^{\circ} \mathrm{C}$. As mentioned, it is assumed that no water exists in the radiator's surface and therefore the boundary is assumed to be aluminium. The effect of water is studied at the end of this section.

Fig. 9 illustrates the variation of PCM average temperature in terms of time for different cases in the discharging mode. The first sharp drop in the temperature profile is related to the temperature reduction from the initial temperature $\left(60{ }^{\circ} \mathrm{C}\right)$ to the liquidus temperature $\left(54{ }^{\circ} \mathrm{C}\right)$ when the phase change process is started. For the porous-PCM alterna- 

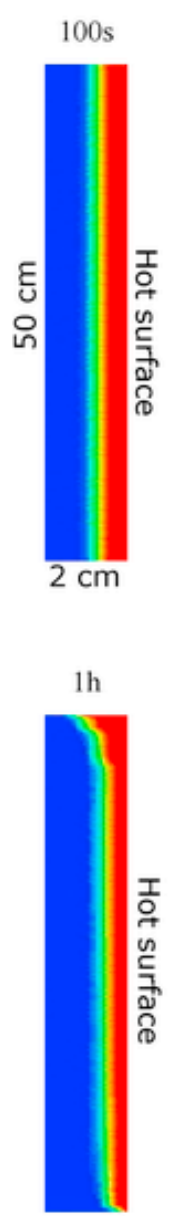

200 s

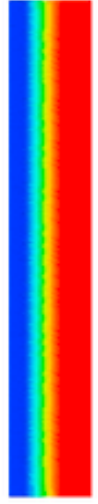

$300 \mathrm{~s}$

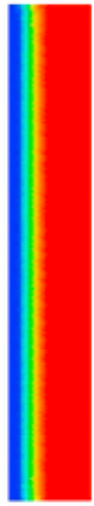

$3 \mathrm{~h}$

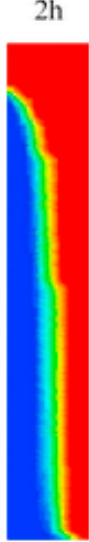

400 s

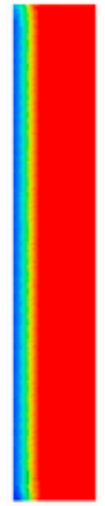

a)

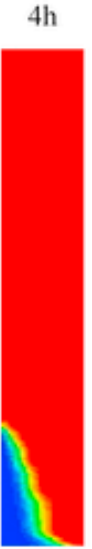

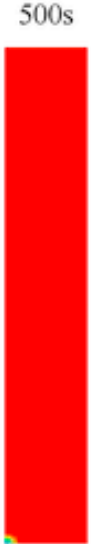

$600 \mathrm{~s}$

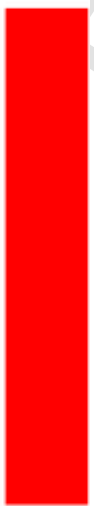

$6 \mathrm{~h}$

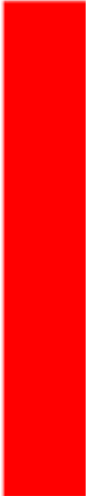

b)

Fig. 7. The liquid fraction contour plots for a) porous-PCM and b) PCM-only alternatives.

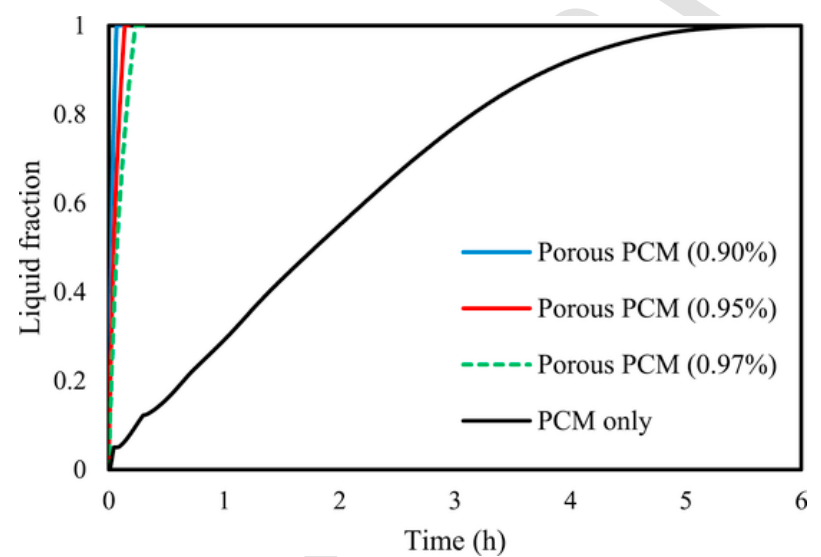

Fig. 8. The variation of the liquid fraction for the porous-PCM cases with different porosity compared with PCM-only alternative.

tives, during the phase change process, the average temperature is almost constant changing from $54{ }^{\circ} \mathrm{C}$ to $53^{\circ} \mathrm{C}$. In addition to the influence of aluminium foam, a small difference between the solidus and liquidus temperature of the PCM material helps to have an almost con-
Table 3

The charging time, energy storage capacity and rate of heat storage for different cases.

\begin{tabular}{|c|c|c|c|c|}
\hline & $\begin{array}{l}\text { Charging } \\
\text { time (s) }\end{array}$ & $\begin{array}{l}\text { Time-saving compared } \\
\text { with PCM-only alternative } \\
(\%)\end{array}$ & $\begin{array}{l}\text { Heat } \\
\text { storage } \\
\text { capacity } \\
(\mathrm{kJ})\end{array}$ & $\begin{array}{l}\text { Heat } \\
\text { storage } \\
\text { rate (W) }\end{array}$ \\
\hline $\begin{array}{l}\text { Porous- } \\
\text { PCM } \\
(\varepsilon=0.9)\end{array}$ & 245 & 98.8 & 2262.6 & 9235.0 \\
\hline $\begin{array}{l}\text { Porous- } \\
\text { PCM } \\
(\varepsilon=0.95)\end{array}$ & 510 & 97.5 & 2266.1 & 4443.3 \\
\hline $\begin{array}{l}\text { Porous- } \\
\text { PCM } \\
(\varepsilon=0.97)\end{array}$ & 875 & 95.8 & 2276.7 & 2601.9 \\
\hline PCM-only & 20625 & - & 2292.8 & 111.2 \\
\hline
\end{tabular}

stant temperature during the phase change process. After that, the temperature drops sharply for the second time. For the PCM-only alternative, the average temperature drops slowly due to the low thermal con- 


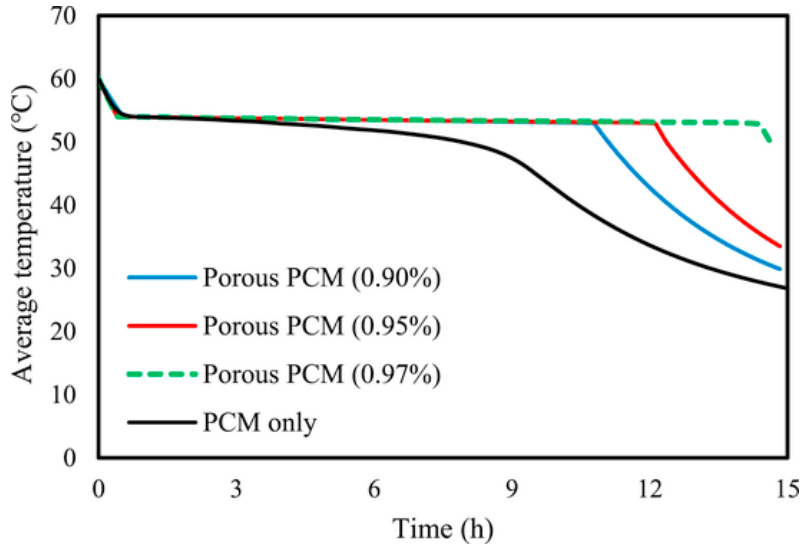

Fig. 9. The variation of PCM average temperature in terms of time for different cases in the discharging process. ductivity of PCM. After $9 \mathrm{~h}$, the rate of temperature reduction accelerates.

Fig. 10-a, 10-b, and 10-c show the variation of temperatures at different points in $\mathrm{x}, \mathrm{y}$ and $\mathrm{z}$ directions, respectively, for the porous-PCM alternative with the porosity of $95 \%$ compared with the PCM-only. The temperatures do not vary significantly at different points for the porous-PCM alternative due to the existence of aluminium foam. The high conductivity porous medium makes a uniform temperature distribution in the domain. For the PCM-only alternative, except the points in the $\mathrm{z}$-direction, the temperatures change in the $\mathrm{x}$ and $\mathrm{y}$-directions. For the points closer to the front wall in the x-direction, a lower temperature is achieved through the time since more heat is released from the PCM. Note that $\mathrm{x}$-direction is perpendicular to the front wall and $\mathrm{y}$-direction is along the gravity direction. In the y-direction, due to buoyancy force and circulation of the liquid PCM, the PCM solidifies from the bottom and therefore the temperatures of the points rise from the bottom to the top layers of the unit. In both cases, when the liquid fraction reaches to zero at a point, the temperature drops sharply since

Porous-PCM
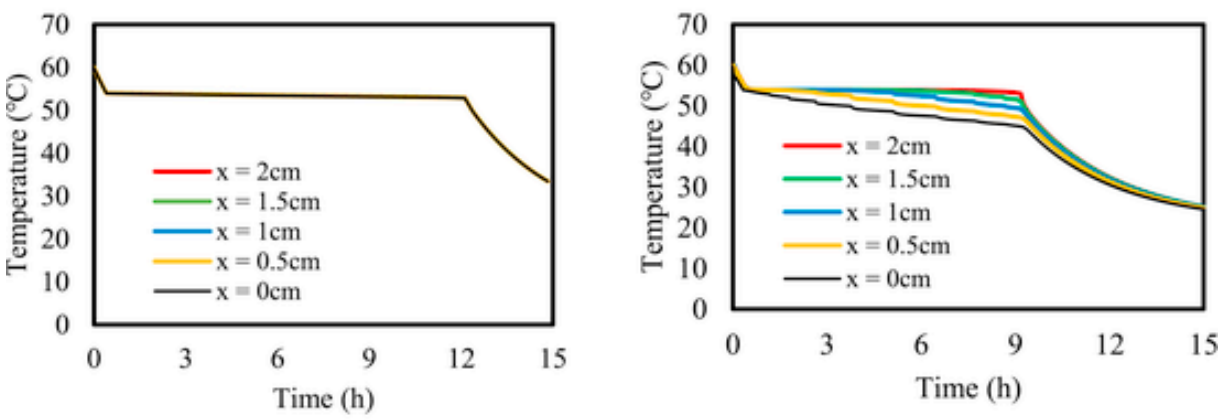

a)
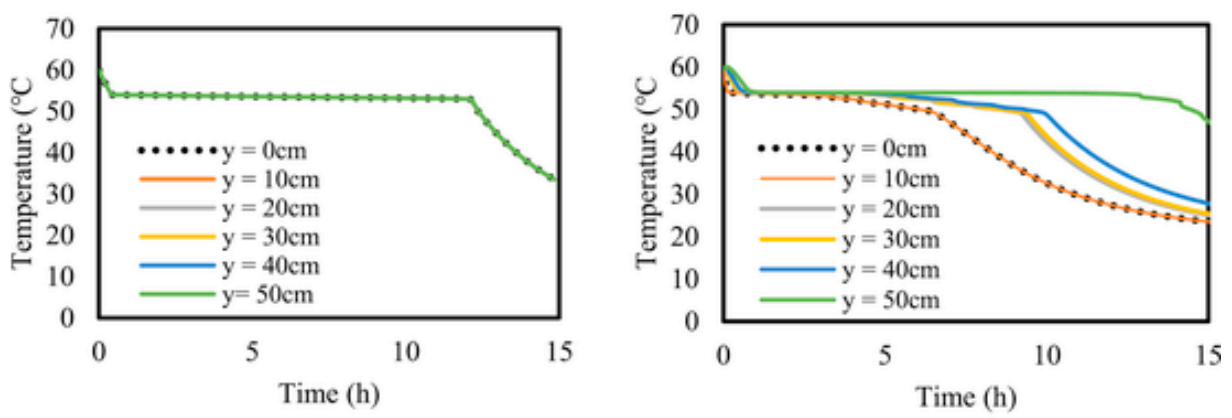

b)
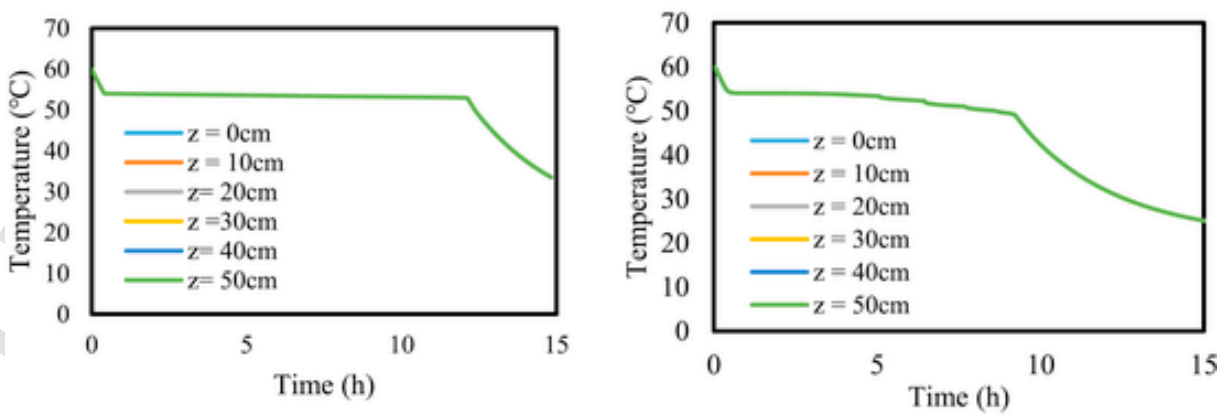

c)

Fig. 10. The variation of temperature at different points in a) x-direction, b) y-direction and c) z-direction for both porous-PCM and PCM-only systems. 
that the point is now placed in the sensible heat part of the discharging mode.

Fig. 11 illustrates the liquid fraction contours at 1-h time intervals for the porous-PCM alternative with the porosity of $95 \%$ compared with the PCM-only alternative. Due to the presence of metal foam, a more uniform liquid fraction distribution can be seen for the porous-PCM alternative compared with the PCM-only alternative. The heat releases from the front wall to the room which is the right wall in the pictures below. Therefore, PCM starts to solidify from the right region to the left. Due to the existence of aluminium foam in the porous-PCM alternative, the solidification process takes place in all the domain more uniformly compared with the PCM-only alternative with a lower liquid fraction in the right region due to the employed boundary condition. For the PCM-only alternative, natural convection causes liquid PCM circulation in the domain, which helps the heat transfer mechanism.

Fig. 12 plots the liquid fraction variation for the proposed cases. In contrast to the charging mode when the liquid fraction increases very fast for the porous-PCM alternatives, the liquid fraction reduces slowly in the discharging mode. This is because heat is recovered by convection heat transfer mechanism from the CLHS unit, which is small compared to the case in the charging mode where the relatively high wall temperature is constantly causing a large amount of heat transfer to the domain. Furthermore, the liquid fraction of the porous-PCM alternative is higher than that for the PCM-only alternative for the first $10 \mathrm{~h}$ and the total discharging time of the porous-PCM alternative is less than that for the PCM-only alternative. Moreover, by reducing the porosity of the metal foam, the discharging time reduces due to a higher amount of metal foam in the domain.

Fig. 13 plots the heat flux variation emitted from the front wall in the symmetry condition in terms of time for different alternatives. The heat flux is almost constant during the phase change process for the porous-PCM alternative, which is higher than that for the PCM-only alternative. Furthermore, by increasing the amount of Aluminium in the matrix, higher heat flux exits from the unit. Note that the difference between the emitted heat flux from the porous-PCM alternative and PCM-only unit increases through the time.

Fig. 14 illustrates the average temperature variation of the front wall in terms of time for different cases. As shown, for the PCM-only alternative, the wall temperature always reduces. However, for the porous-PCM alternatives, the unit surface temperature is kept constant until the end of the solidification process. Therefore, the system is capable to provide a constant temperature on the surfaces of the unit and radiator. As mentioned, the masses of PCM for different cases are kept constant. As shown in Fig. 13, for the lower porosity, a higher amount of heat flux is emitted from the front surface and therefore as shown in Fig. 12, the discharging time of the system with lower porosity is less. However, as shown in Fig. 14, all porous-PCM units can provide a con-
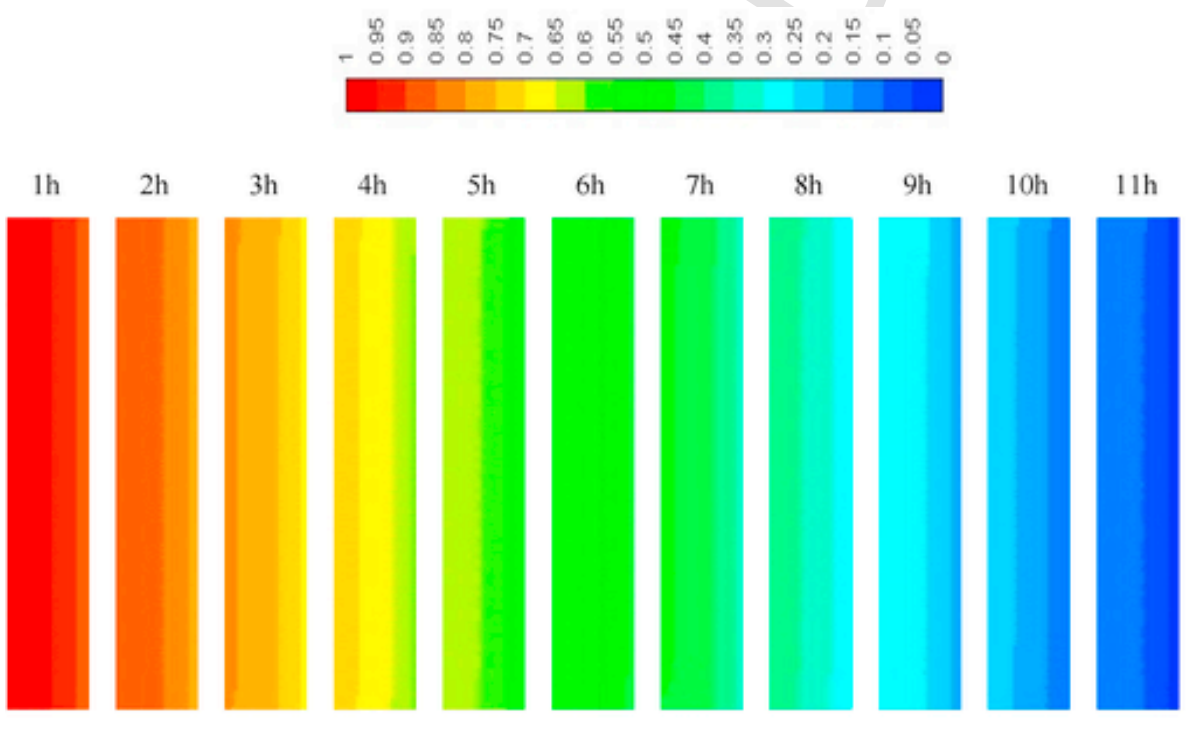

a)
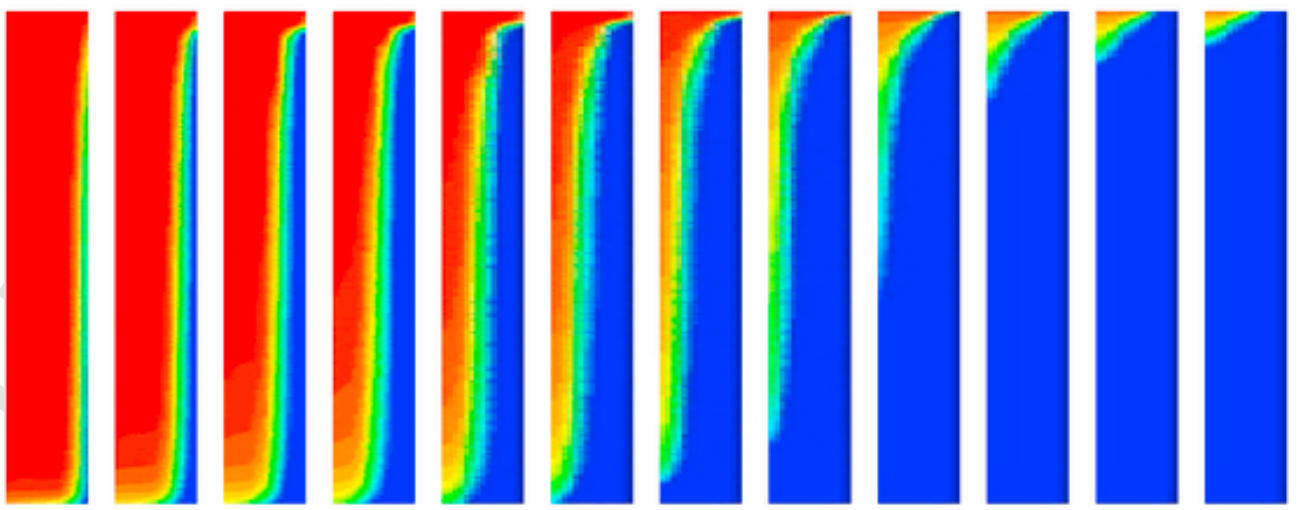

b)

Fig. 11. The contour plots of the liquid fraction at 1-h time interval for a) porous-PCM and b) PCM-only alternative. 


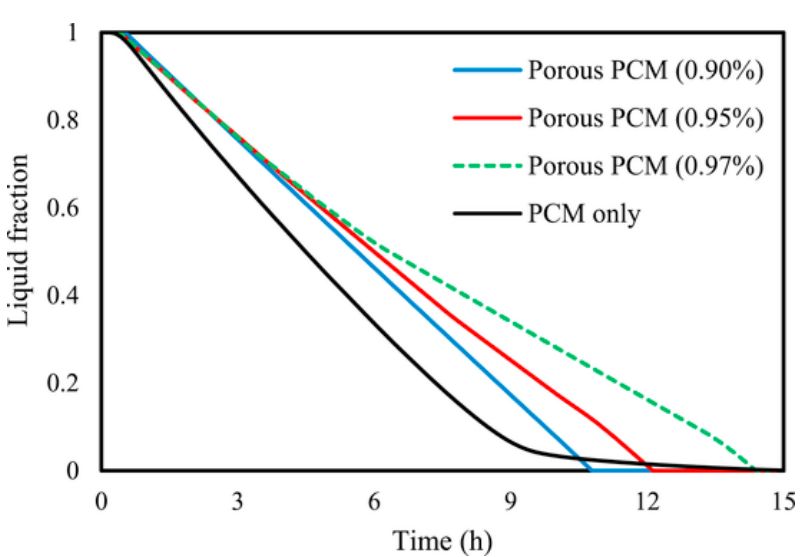

Fig. 12. Liquid fraction variation for the proposed cases.

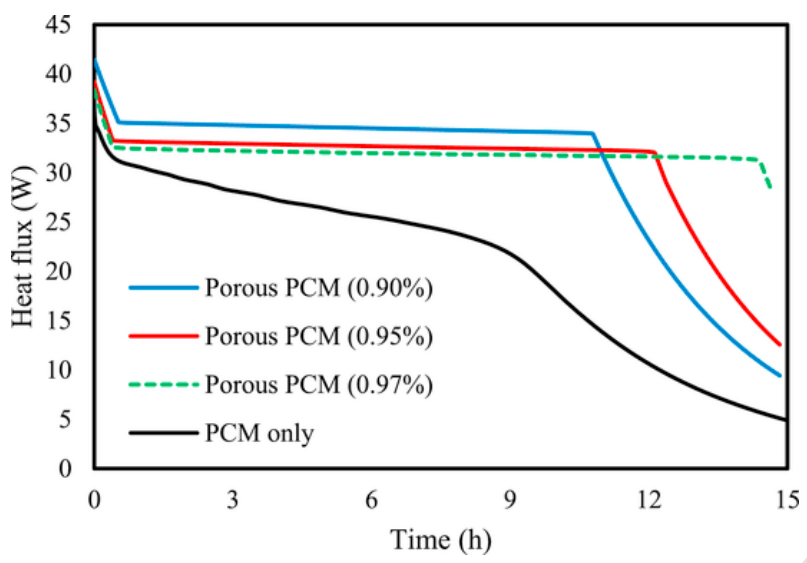

Fig. 13. The variation of emitted heat flux from the front wall for different studied cases in the symmetry condition.

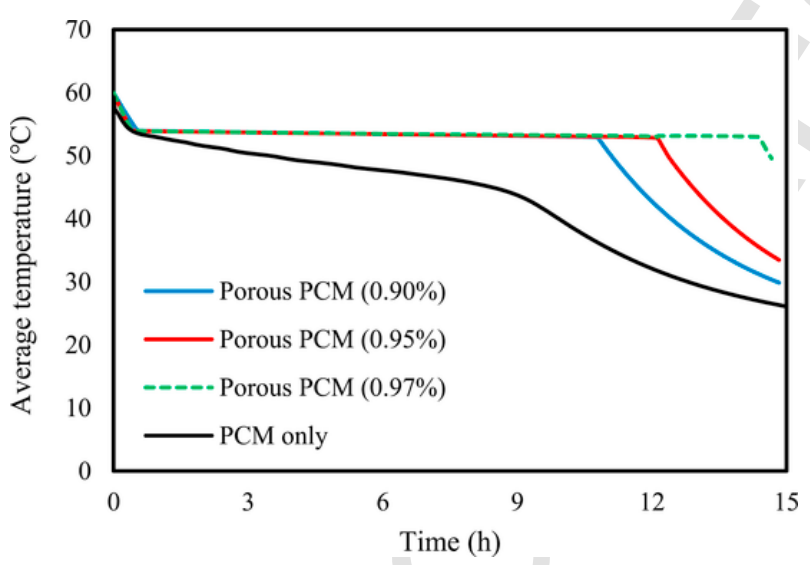

Fig. 14. The average temperature of the front wall in terms of time for different studied cases.

stant temperature for the front wall during the discharging time. Therefore, a system with a higher porosity is preferable.

Table 4 summarizes the discharging time, the total heat retrieval capacity and rate of heat retrieval from the porous-PCM alternatives compared with the PCM-only alternative. The percentage of time-saving compared with the PCM-only unit is also presented. Note that the amount of heat recovery capacity is calculated until the liquid fraction reaches zero. For the PCM-only alternative, since the heat transfer process happens slowly from the right side of the storage unit to the left side due to low thermal conductivity of the PCM, the PCM uses the latent and sensible heat simultaneously, and therefore a lower
Table 4

The discharging time, heat retrieval capacity and rate of heat retrieval for different cases.

\begin{tabular}{lllll}
\hline & & $\begin{array}{l}\text { Time-saving compared } \\
\text { with PCM-only case } \\
(\%)\end{array}$ & $\begin{array}{l}\text { Heat } \\
\text { retrieval } \\
\text { capacity } \\
\text { disch) }\end{array}$ & $\begin{array}{l}\text { Heat } \\
\text { retrieval } \\
\text { rate }(\mathrm{W})\end{array}$ \\
\hline $\begin{array}{l}\text { Porous- } \\
\text { PCM } \\
(\varepsilon=0.9)\end{array}$ & 10.97 & 48.01 & -2143.4 & -44.8 \\
$\begin{array}{l}\text { Porous- } \\
\text { PCM } \\
(\varepsilon=0.95)\end{array}$ & 12.32 & 41.67 & -2145.8 & -39.9 \\
$\begin{array}{l}\text { Porous- } \\
\text { PCM } \\
(\varepsilon=0.97)\end{array}$ & 14.79 & 29.96 & -2157.0 & -33.4 \\
PCM-only & 21.11 & 0 & & \\
\hline
\end{tabular}

mean PCM temperature is achieved at the end of the solidification process results in a higher amount of heat retrieval capacity. However, in the porous-PCM alternative, due to the presence of aluminium foam, the PCM solidifies entirely and therefore after the heat recovery process, the temperature is almost equal to the solidus temperature entirely. The rate of heat retrieval enhances by using a metal foam with lower porosity with a negligible difference in the capacity input.

In the discharging mode, it can be concluded that the stored energy in the charging mode is released to the air in almost $12 \mathrm{~h}$ which can provide a uniform temperature on the surface of the radiator similar to the existence of hot water for the porous-PCM alternatives. From Fig. 14 , the presence of porous medium in the energy storage unit provides a uniform temperature on the front wall, whereas, without the foam, temperature constantly decreases.

In reality, different types of radiators are employed for space heating. For a typical radiator, water tubes are placed at the external surface and cover almost $50 \%$ of the surface and the other $50 \%$ consisting of bonded metallic plate separating the vertical water channels. Therefore, for the proposed energy storage unit, for almost $50 \%$ of the unit, a layer of water exists between the composite PCM and air. The presence of the water layer, on one hand, reduces the surface temperature of the front wall when a convection boundary condition is considered (for $50 \%$ of the unit). On the other hand, it reduces the released heat from the PCM to the air causing a higher solidification time. Therefore, to better understand the effect of the intermittent water layer on the performance of the unit, a 2-D simulation is performed considering the porous-PCM alternative (with $95 \%$ porosity) with the same dimensions $(2 \mathrm{~cm} \times 50 \mathrm{~cm})$ with a unit depth and a water layer with $1 \mathrm{~cm}$ thickness and the same height. The boundary conditions are considered similar to the 3-D simulation mentioned in section 2. Fig. 15 illustrates the variation of mean temperatures of the PCM, water, mid-wall between the PCM and water as well as the front wall. The solidification time increases to $36.26 \mathrm{~h}$ due to the presence of the water layer. The maximum difference between the temperature of the water-separated front wall (facing room air) and mid-wall (facing PCM and foam) is less than $2{ }^{\circ} \mathrm{C}$. Due to the presence of high conductivity porous medium and also small thickness of the PCM container, the average temperature of the PCM and mid-wall is almost the same.

The energy stored in the unit comes from the radiator which affects the performance of the radiator and also the room. The thermal energy is captured and insulated which otherwise losses to the walls in order to have a slow release to the radiator at a later time. As mentioned before, the main idea of the proposed product is peak-shaving. The energy storage unit can gain energy from the back surface of a radiator during the night (or off-peak hours) and then instead of using the boiler or electrical elements in peak-hours, the product provides a uniform temperature on the surface of the radiator. Furthermore, due to 


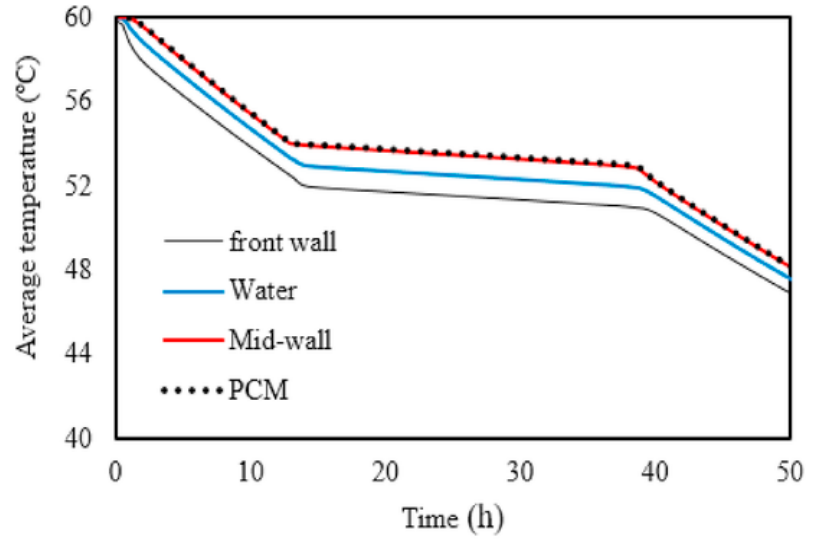

Fig. 15. The effect of considering a water tube between the CLHS unit and the air on the mean temperatures of PCM, water, mid-wall and front wall.

the large surface of the radiator and the presence of metal foam which increases the rate of heat transfer significantly, the unit is charged quickly in less than $15 \mathrm{~min}$; however, the unit discharges the stored thermal energy and provides a uniform surface temperature for more than $10 \mathrm{~h}$. Therefore, instead of using the boiler, the product can provide an almost similar temperature on the surface of the radiator and therefore in this way, the proposed design can potentially result in energy saving.

\section{Conclusion}

The idea of using a CLHS system in the back of the radiator was introduced to demonstrate that the combination can provide a uniform temperature on the radiator's surface when the boiler is turned off. A high conductivity porous medium enhances the heat transfer inside the PCM. The existence of a porous medium, as well as the 'almost constant' melting temperature of the PCM, helps to provide uniform temperature in the discharging mode. Different porosities of the metal foam were examined compared to the PCM-only alternative in order to compare the material usage and size of the heat storage. The CLHS unit provides a constant temperature on the unit surface for almost $11 \mathrm{~h}$. The charging time for the porous-PCM alternatives is less than 15 min due to the big surface area of the heat source and the presence of metal foam. For the PCM-only alternative, the charging and discharging times are almost $5.7 \mathrm{~h}$ and $21 \mathrm{~h}$, respectively. During the discharging process, the surface temperature reduces continuously for the PCM-only alternative. The results of this study lay the foundation for a novel design of a compact unit for energy consumption reduction for space heating used in buildings. The product idea developed in this study helps energy-saving and peak-shaving in buildings with consequent improvement for environmental sustainability. Experimental investigations to practically support the results of this study are now required as a step toward commercializing the product.

\section{Declaration of competing interest}

The authors declare the following financial interests/personal relationships which may be considered as potential competing interests: This work was funded by grants from EPSRC (Engineering and Physical Sciences Research Council) from the United Kingdom.

\section{Acknowledgement}

This work was funded by the EPSRC (Engineering and Physical Sciences Research Council) via Supergen Energy Storage II, grant refer- ence EP/P003435/1, titled 'nano-Structured PCM Composites for Compact Space Heating: n-CoSH'.

\section{Appendix A. Supplementary data}

Supplementary data to this article can be found online at https://doi. org/10.1016/j.jclepro.2020.120504.

\section{References}

Al-Abidi, A.A., Mat, S., Sopian, K., Sulaiman, M.Y., Mohammad, A.T., 2013. Internal and external fin heat transfer enhancement technique for latent heat thermal energy storage in triplex tube heat exchangers. Appl. Therm. Eng. 53 (1), 147-156.

Assis, E., Katsman, L., Ziskind, G., Letan, R., 2007. Numerical and experimental study of melting in a spherical shell. Int. J. Heat Mass Tran. 50 (9), 1790-1804.

Beis, March 2017. 2016 UK GREENHOUSE GAS EMISSIONS, PROVISIONAL FIGURES. Department for Business, Energy \& Industrial Strategy (BEIS).

Bejan, A., 2013. Convection Heat Transfer. John wiley \& sons.

BIES, July 2017. Energy Consumption in the UK. Department of Business, Energy, and Industrial Strategy. BIES.

Campos-Celador, Á., Diarce, G., Zubiaga, J.T., Bandos, T.V., García-Romero, A.M., López, L., Sala, J.M., 2014. Design of a finned plate latent heat thermal energy storage system for domestic applications. Energy Procedia 48, 300-308.

Dadollahi, M., Mehrpooya, M., 2017. Modeling and investigation of high temperature phase change materials (PCM) in different storage tank configurations. J. Clean. Prod. 161, 831-839.

Dechesne, B., Gendebien, S., Martens, J., Lemort, V., 2014. Designing and testing an air-PCM heat exchanger for building ventilation application coupled to energy storage. In: 15th International Refrigeration and Air Conditioning Conference. Purdue.

El-Said, E., Abdulaziz, M., Awad, M., 2018. Thermodynamic performance evaluation for helical plate heat exchanger based on second law analysis. Proc. Rom. Acad. Math. Phys. Tech. Sci. Inf. Sci. 19, 237-242.

El-Said, E.M.S., Abou Al-Sood, M.M., 2019. Shell and tube heat exchanger with new segmental baffles configurations: a comparative experimental investigation. Appl. Therm. Eng. 150, 803-810.

El-Said, E.M.S., Alsood, M.M.A., 2018. Experimental investigation of air injection effect on the performance of horizontal shell and multi-tube heat exchanger with baffles. Appl. Therm. Eng. 134, 238-247.

Irshad, K., Habib, K., Saidur, R., Kareem, M.W., Saha, B.B., 2019. Study of thermoelectric and photovoltaic facade system for energy efficient building development: a review. J. Clean. Prod. 209, 1376-1395.

Jamekhorshid, A., Sadrameli, S.M., Farid, M., 2014. A review of microencapsulation methods of phase change materials (PCMs) as a thermal energy storage (TES) medium. Renew. Sustain. Energy Rev. 31, 531-542.

Kabeel, A.E., Abdelaziz, G.B., El-Said, E.M.S., 2019. Experimental investigation of a solar still with composite material heat storage: energy, exergy and economic analysis. J. Clean. Prod. 231, 21-34.

Kabeel, A.E., Sathyamurthy, R., El-Agouz, S.A., Manokar, A., El-Said, E., 2019. Experimental investigation on inclined PV panel solar still with cover cooling and PCM. J. Therm. Anal. Calorim.

Khan, Z., Khan, Z., Ghafoor, A., 2016. A review of performance enhancement of PCM based latent heat storage system within the context of materials, thermal stability and compatibility. Energy Convers. Manag. 115, 132-158.

Li, Z., Shahsavar, A., Al-Rashed, A.A., Talebizadehsardari, P., 2020. Effect of porous medium and nanoparticles presences in a counter-current triple-tube composite porous/nano-PCM system. Appl. Therm. Eng. 167, 114777.

Liu, Z., Yao, Y., Wu, H., 2013. Numerical modeling for solid-liquid phase change phenomena in porous media: shell-and-tube type latent heat thermal energy storage. Appl. Energy 112, 1222-1232.

Mahdi, J.M., Mohammed, H.I., Hashim, E.T., Talebizadehsardari, P., Nsofor, E.C., 2020. Solidification enhancement with multiple PCMs, cascaded metal foam and nanoparticles in the shell-and-tube energy storage system. Appl. Energy 257, 113993.

Mahdi, J.M., Nsofor, E.C., 2017. Melting enhancement in triplex-tube latent heat energy storage system using nanoparticles-metal foam combination. Appl. Energy 191, 22-34.

Mahdi, J.M., Nsofor, E.C., 2018. Multiple-segment metal foam application in the shell-and-tube PCM thermal energy storage system. J. Energy Storage 20, 529-541.

Marique, A.-F., De Meester, T., De Herde, A., Reiter, S., 2014. An online interactive tool to assess energy consumption in residential buildings and for daily mobility. Energy Build. 78, 50-58.

Mat, S., Al-Abidi, A.A., Sopian, K., Sulaiman, M.Y., Mohammad, A.T., 2013. Enhance heat transfer for PCM melting in triplex tube with internal-external fins. Energy Convers. Manag. 74, 223-236.

Mesalhy, O., Lafdi, K., Elgafy, A., Bowman, K., 2005. Numerical study for enhancing the thermal conductivity of phase change material (PCM) storage using high thermal conductivity porous matrix. Energy Convers. Manag. 46 (6), 847-867.

Mohammed, H.I., Sardari, P.T., Giddings, D., 2019. Multiphase flow and boiling heat transfer modelling of nanofluids in horizontal tubes embedded in a metal foam. Int. J. Therm. Sci. 146, 106099.

Osterman, E., Butala, V., Stritih, U., 2015. PCM thermal storage system for 'free' heating and cooling of buildings. Energy Build. 106, 125-133.

Pereira da Cunha, J., Eames, P., 2016. Thermal energy storage for low and medium temperature applications using phase change materials - a review. Appl. Energy 177, $227-238$.

Py, X., Olives, R., Mauran, S., 2001. Paraffin/porous-graphite-matrix composite as a high and constant power thermal storage material. Int. J. Heat Mass Tran. 44 (14), 2727-2737. 
Rubitherm GmbH, RT54HC Data Sheet.

Sarbu, I., Sebarchievici, C., 2016. Solar Heating and Cooling Systems: Fundamentals, Experiments and Applications. Elsevier Science.

Sardari, P.T., Giddings, D., Grant, D., Gillott, M., Walker, G.S., 2020. Discharge of a composite metal foam/phase change material to air heat exchanger for a domestic thermal storage unit. Renew. Energy 148, 987-1001.

Sardari, P.T., Grant, D., Giddings, D., Walker, G.S., Gillott, M., 2019. Composite metal foam/PCM energy store design for dwelling space air heating. Energy Convers. Manag. 201, 112151.

Sardari, P.T., Mohammed, H.I., Giddings, D., Gillott, M., Grant, D., 2019. Numerical study of a multiple-segment metal foam-PCM latent heat storage unit: effect of porosity, pore density and location of heat source. Energy 116108.

Sardari, P.T., Walker, G.S., Gillott, M., Grant, D., Giddings, D., 2019. Numerical modelling of phase change material melting process embedded in porous media: effect of heat storage size. Proc. IME J. Power Energy.

Shahsavar, A., Al-Rashed, A.A.A.A., Entezari, S., Sardari, P.T., 2019. Melting and solidification characteristics of a double-pipe latent heat storage system with sinusoidal wavy channels embedded in a porous medium. Energy 171, 751-769.

Shahsavar, A., Goodarzi, A., Mohammed, H.I., Shirneshan, A., Talebizadehsardari, P., 2019. Thermal performance evaluation of non-uniform fin array in a finned double-pipe latent heat storage system. Energy 116800.

Shahsavar, A., Khosravi, J., Mohammed, H.I., Talebizadehsardari, P., 2020. Performance evaluation of melting/solidification mechanism in a variable wave-length wavy channel double-tube latent heat storage system. J. Energy Storage 27, 101063.

Shahsavar, A., Shaham, A., Talebizadehsardari, P., 2019. Wavy channels triple-tube LHS unit with sinusoidal variable wavelength in charging/discharging mechanism. Int. Commun. Heat Mass Tran. 107, 93-105.

Shaibani, A.R., Keshtkar, M.M., Sardari, P.T., 2019. Thermo-economic analysis of a cold storage system in full and partial modes with two different scenarios: a case study. J. Energy Storage 24, 100783.

Shang, B., Hu, J., Hu, R., Cheng, J., Luo, X., 2018. Modularized thermal storage unit of metal foam/paraffin composite. Int. J. Heat Mass Tran. 125, 596-603.

Sheikholeslami, M., 2018. Numerical modeling of nano enhanced PCM solidification in an enclosure with metallic fin. J. Mol. Liq. 259, 424-438.

Sheikholeslami, M., 2018. Numerical simulation for solidification in a LHTESS by means of Nano-enhanced PCM. J.Taiwan.Inst. Chem. Eng. 86, 25-41.

Sheikholeslami, M., Mahian, O., 2019. Enhancement of PCM solidification using inorganic nanoparticles and an external magnetic field with application in energy storage systems. J. Clean. Prod. 215, 963-977.

Wang, P., Wang, X., Huang, Y., Li, C., Peng, Z., Ding, Y., 2015. Thermal energy charging behaviour of a heat exchange device with a zigzag plate configuration containing multi-phase-change-materials (m-PCMs). Appl. Energy 142, 328-336.

Wang, X., Liu, J., Zhang, Y., Di, H., Jiang, Y., 2006. Experimental research on a kind of novel high temperature phase change storage heater. Energy Convers. Manag. 47 (15-16), 2211-2222.

Xiao, X., Zhang, P., Li, M., 2013. Preparation and thermal characterization of paraffin/ metal foam composite phase change material. Appl. Energy 112, 1357-1366.

Xu, Y., Ren, Q., Zheng, Z.-J., He, Y.-L., 2017. Evaluation and optimization of melting performance for a latent heat thermal energy storage unit partially filled with porous media. Appl. Energy 193, 84-95.

Ye, W.-B., Zhu, D.-S., Wang, N., 2011. Numerical simulation on phase-change thermal storage/release in a plate-fin unit. Appl. Therm. Eng. 31 (17), 3871-3884.

Yong, J.Y., Klemeš, J.J., Varbanov, P.S., Huisingh, D., 2016. Cleaner energy for cleaner production: modelling, simulation, optimisation and waste management. J. Clean. Prod. 111, 1-16.

Yu, Z., Gou, Z., Qian, F., Fu, J., Tao, Y., 2019. Towards an optimized zero energy solar house: a critical analysis of passive and active design strategies used in Solar Decathlon Europe in Madrid. J. Clean. Prod. 236, 117646.

Zhang, P., Meng, Z.N., Zhu, H., Wang, Y.L., Peng, S.P., 2017. Melting heat transfer characteristics of a composite phase change material fabricated by paraffin and metal foam. Appl. Energy 185, 1971-1983.

Zhao, C., 2012. Review on thermal transport in high porosity cellular metal foams with open cells. Int. J. Heat Mass Tran. 55 (13-14), 3618-3632. 